\title{
OTT as New Platform of Cinema Exhibition: Opportunities and Challenges for Kannada Films
}

\author{
N. Vinod Rao ${ }^{1}$ and R. Rajeshwari ${ }^{2}$ \\ ${ }^{1}$ Research Scholar, ${ }^{2}$ Assistant Professor \\ ${ }^{1 \& 2}$ Department of Electronic Media, Bangalore University, Karnataka, India \\ E-mail: vinodraon24@gmail.com, rajeshwari.rnayak@gmail.com
}

\begin{abstract}
COVID-19 pandemic has affected many areas including cinema exhibitions. Due to non-opening of cinema theatres film makers found the platform that is over-the-top (OTT). Before COVID-19 OTT was not able to compete with theatrical release. However, the pandemic situations changed the way of movie release through OTT platforms such as Netflix, Amazon Prime, Hot-star and others. The usage of OTT increased during the period of lockdown. According to Boston Consulting Group, subscriptions increased $60 \%$ and average watching hours increased to $14.5 \%$. In the Kannada film industry, the well-known actor and producer Punith Rajkumar's two films titled Law and French Biriyani were released on India's second largest OTT platform Amazon Prime during the lockdown period. In this context, this research tried to find prospects of Kannada film exhibition through OTT platform. The specific objectives are to explore the opportunities for releasing Kannada films through OTT, to study the challenges ahead in this way. The study used both quantitative and qualitative research methods. Online surveys conducted with structured questionnaires among 100 OTT users and in-depth interviews conducted among the people who are involved in film making from Kannada film industry to answer the research questions. This study would help filmmakers who are intended to release their film through OOT in future.

Keywords: OTT, Exhibition, Kannada, Opportunity, Challenge, COVID-19
\end{abstract}

\section{INTRODUCTION}

We are living in the era of transformation and technology which is playing a significant role in the field of mass media. Amongst mass media, cinema is one of the major media where all other mass media such as radio, newspaper, television and others depends on cinema for content. The content may be comedy, action, video song, audio song, gossip stories of stars etc. Cinema has many platforms for its broadcast but theatre is the first platform to release new films. Due to COVID-19 the theatres were closed. Many films which were ready for release and yet to be released started looking for alternatives. This was the situation which opened the way for future broadcasting medium over-thetop (OTT) to overtake the place of theatre. $79 \%$ smart phone users in India are using OTT apps for entertainment and as many as four out of five users have at least one OTT entertainment platform on their device, a new report said on Thursday. Hot-star is the most-penetrated OTT entertainment app with $49 \%$ of smart phone users having it installed on their devices. (IANS, 2019)Earlier OTT was the platform for Web Series, newcomers and experimental films, but now big budget and stardom films are also getting released on it. For example in Bollywood Shakunthala Devi, in Kannada French Biriyani, in Tamil Soorarai Pottru and many films released pan India. For small budget films OTT may be the alternate option, but for big budget films theatrical release is the only way to get back the returns. Because theatre release has a wider revenue opportunity. With respect to censorship issues, the content of OTT platforms has to comply with law of the country. But OTT content doesn't have to apply for censorship.OTT can be used in mobile, computer, android TV and android set top box. Therefore, it has become very popular platform for entertainment. One should not forget the contribution of 4G network and Jio internet services which also complemented to OTT user devices.

Kannada film Industry is one of the important film industries amongst all other Indian film industries. There are a mixture of big and small budget films produced in the industry. Every year there are about 120 film released in Kannada language. Releasing film in a theatre is big celebration in the industry. Producers reserve some money to release the film in theatre such as decoration, cut out etc. Even film star's fans also eagerly wait for their favorite star film to release in theatre. But COVID-19 has changed the way of film release throughout the world. Big budget film producers and stars are ready to release their film on OTT.

\section{STATEMENT OF THE PROBLEM}

This research focused on the challenges and opportunities of using OTT as new platform to release a film. The researcher sought answer for the following question: "Whether OTT can be used as new platform for cinema exhibition? What are the opportunities and challenges?”

\section{LITERATURE REVIEW}

According to Kamal Gianchandani, CEO, PVR Picture "We are disappointed with some of our producers deciding to go straight to the streaming platform/s. We were hoping that the producers would accede to our request to hold back their film's release till cinemas reopen.”Domestic cinema theatres contribute $57 \%$ of total film producers' revenue and another $18 \%$ comes from overseas cinemas, whereas digital 
rights/OTT rights share is only $12-13 \%$ (Pawan \& Kamal, 2020). Theatrical releases will always yield wider revenue opportunities then that accrued from OTT platforms. The new 100 crore club, usually seen as an extension of the old lexicon diamond jubilee, is a testament to the revenue amalgamating power of blockbuster films on bigger screens. However, desperate times have always called for desperate measures. In a country with lower screen penetration, both multiplexes and single-screen theatres are going to be adversely affected by the alternating lifestyle post-COVID19. It is expected or speculated that the leisure and luxury of cinema will become a more expensive endeavor (Priyal, 2020).

In the article published in community explains how the future of OTT is in India, according to the article, to capture customers telecom carriers such as Airtel, Jio and others are offering monthly / annual subscriptions of OTT platform to feed a content-hungry of its customer. Reach of 3G internet and Android Mobiles for cheaper rate helping OTT to reach rural India (COMMUNITY, 2020).

In this article author analyses the further of OTT along with Content Censorship. Worldwide it is a mix voice regarding censorship on Internet content including OTT, YouTube, Face book etc.. Content censorship is generally based on hate speech, national security, defamation, political compulsion, cultural insensitivity and so on. There has been a fair share of content censorship such as Netflix's decided to remove the episode of the Patriot Act, which was critical of the Crown Prince of Saudi Arabia.

And in India, Netflix released a censored version of Angry Indian Goddesses. While releasing an uncensored version internationally. There are many similar instances, and the author believes this trend will only grow. However the streaming wars will empower consumers and also revolutionize how they consume media (Shashank, 2020).

The most recent innovation that has tremendously affected the development of OTT is mobile viewing. The emergence of mobile devices such as smart phones, tablets, and ultrabooks has inexorably challenged the boundary between new media and conventional television, reshaping the ways in which programs are both produced and 5 viewers watch them (Ghadialy, 2011).

\section{SCOPE OF THE STUDY}

Many film makers started releasing their films on OTT platform and some other are still following the wait and watch technique. Though OTT has advantages as well as disadvantages definitely it played a crucial role in some of the film industry activities during COVID -19 rules. Hence the present study would help film makers to plan their activity of film release, etc., on OTT platform in future. It also helps policy makers to make law with respect to content of the OTT which is now have no control over it.

\section{OBJECTIVES OF THE STUDY}

The objective of this study is to explore OTT as a new platform for Kannada film release. The specific objectives are to know the opportunities for releasing Kannada films through OTT, to study the challenges ahead in this way and understand the audiences' experience of cinema viewing on a small screen.

\section{METHODOLOGY}

The study used both quantitative and qualitative research methods. Online survey conducted with structured questionnaires among 100 OTT users in and around Bangalore to know the experience of cinema viewing on a small screen. In-depth interviews were conducted among the people who are involved in film making from Kannada film industry such as director, producer, cinematographer, video editor and artist to know the challenges of releasing films on OTT and its future.

\section{DATA ANALYSIS}

Google forms were distributed among respondents who are interested in watching movies. Researcher received 100 responses and among them $54 \%$ were male respondents and $46 \%$ were female respondents.

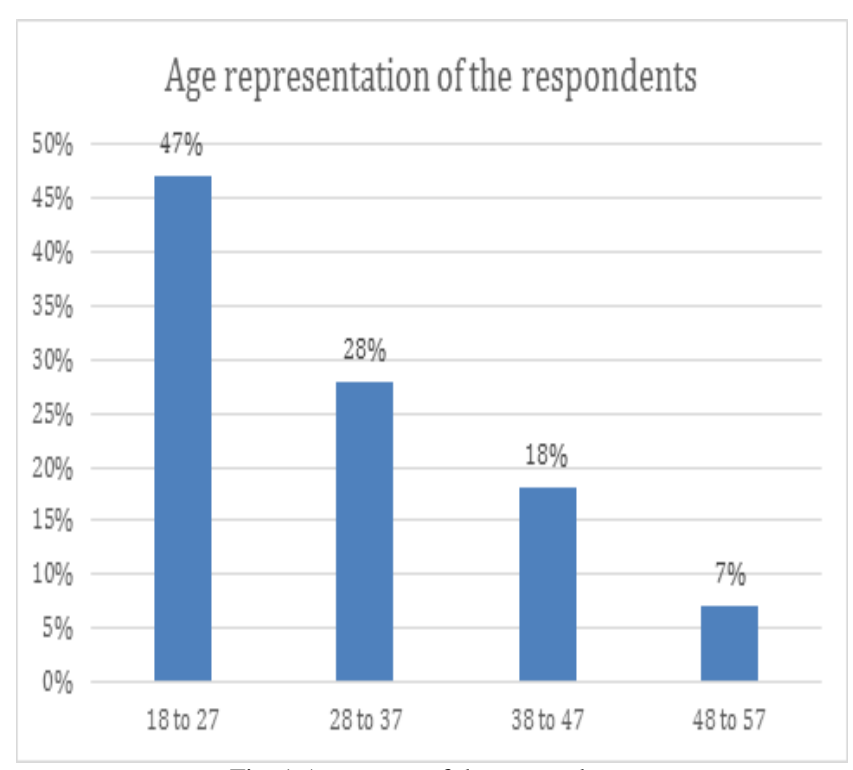

Fig. 1 Age group of the respondents

Among 100 respondents $47 \%$ were between 18 to $27,28 \%$ of the respondents were of 28 to 37 age group, $18 \%$ were from 38 to 47 age group and only $7 \%$ were from 48 to 57 age group. This shows that youths are prominent among respondents.

Majority of the respondents (34\%) were professionals who are doctors, engineers etc, $33 \%$ were students, next to them were private employees (28\%) and 5\% were government employees. 


\section{Frequency of watching movies}

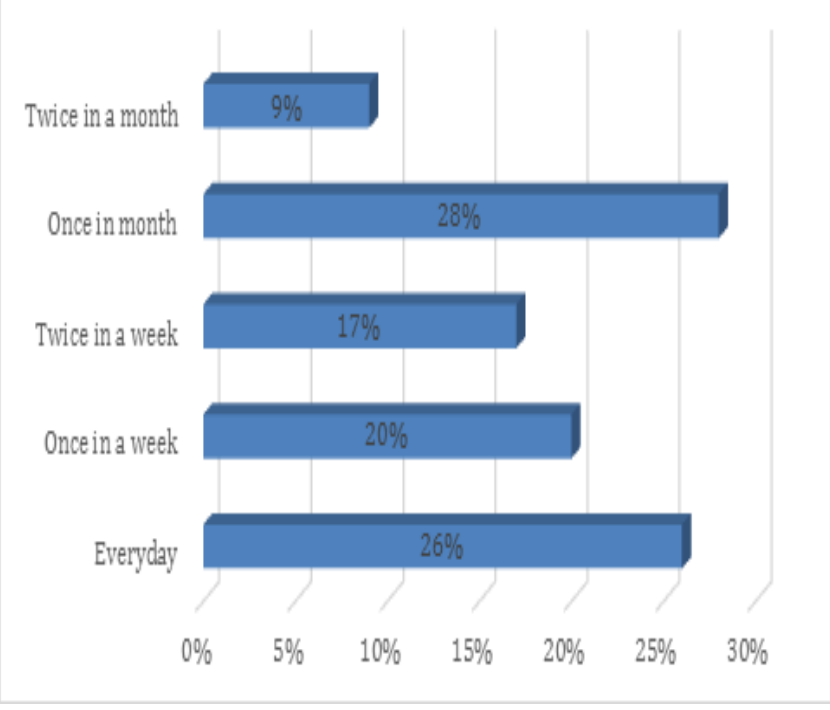

Fig. 2 Frequency of watching movies

All respondents are active movie viewers. 28\% of them watch movies once in a month. $26 \%$ watches it every day. $20 \%$ of them said that once in a week. $17 \%$ of them reacted they watching a movie twice a week and only $9 \%$ of them said it twice in a month. And it is evident that the majority of the respondents are regular viewers of movies.

\section{Movies Watched in last 12 Months}

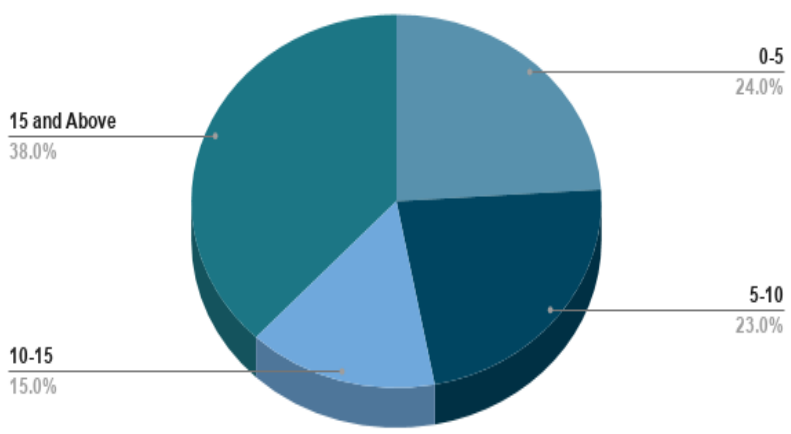

Fig. 3 Films watched in last 12 months

The question was asked how many movies they have watched during last 12 months including lockdown period. Among them 38\% said they have watched more than 15 movies in this period. $15 \%$ of them reacted they have watched 10 to 15 movies. 23\% of the respondents informed that they watched 5 to 10 movies and $24 \%$ of them accepted that they watched up to 5 movies during this time. From last 12-months film theatres were almost closed. Therefore, to know whether respondents' feel comfortable watching movies on small screen i.e. OTT platform the question was asked. Majority of the respondents $(60 \%)$ opined that they are comfortable watching movies on OTT and only $40 \%$ of them revealed that they are not. Further, the question was asked to give the reasons for why and why not they are not comfortable.

Majority of the respondents who said yes agreed that they are comfortable because watching movies on a small screen saves their time, they can take the device with them, more choices are available, they can save time and they can watch wherever and wherever they want. Therefore, they like to watch movies on a small screen. Respondents who reacted no given the following reasons. They prefer to watch movies in the theatre only, they feel irritated or uncomfortable with the small screen, and subscription rate is high and finally network issues.

For the question whether they get same feeling of theatre when they watch movies on small screen only $35 \%$ of the respondents said yes because they use gadgets for theatre sound feeling, they watch movies through TV / home theatre, they create the atmosphere of theatre at home, they just concentrate on the theme and don't care about technical aspects. And majority of them (60\%) said they don't get the same as theatre. Reasons are images are too small to watch, less emotional appeal, poor sound quality, no theatre atmosphere, no feeling of going out with family/friends. Only $15 \%$ said they may get the same feeing but they are not sure about it.

Among respondents 54\% are subscribed to OTT platforms such as Amazon Prime, Netflix, Hotstar, Voot, YouTube etc. and $46 \%$ are not subscribes to OTT platforms. Between subscribers $50 \%$ are using the paid version and $50 \%$ are using the free version of OTT. Among respondents $76 \%$ said in future they prefer to watch movies on both OTT and theatre, $18 \%$ said they like to watch movies only in theatre and only $6 \%$ of them said they are interested to watch movies only on OTT platforms. Therefore, it is substantiated that people are not yet ready to accept OTT as an alternate or new platform for Kannada film exhibition.

\section{A. Interview with Filmmakers}

To know the challenges and opportunities for Kannada cinema in OTT interview was conducted among 6 Kannada film makers such as directors, producers, cinematographers and video editors. The following questions were asked to all of them and their answer is recorded and presented here. One of the eminent director and producer of the Kannada film industry Mr. B. Suresh said that he won't believe` that OTT will be the future exhibition platform for Kannada or any Indian language film. The recent development happened with respect to OTT is just because of pandemic, after pandemic everything will be set to back. There is no difference in production with respect to OTT, only the treatment of presentation and camera shot composition will be changed. OTT has a worldwide market and its user ratio is Kannada is very small. Therefore, Kannada films are not getting good revenue from OTT release. It may become a 
second source of income after theatre release. And in some cases private theatres with 50/100 seats capacity in resorts or apartments may take one subscription from OTT and be watched by many people. Definitely it will affect the revenue.

A film editor from Kannada industry Mr. Prasanth, opined that OTT may give a tough fight to theatre release in future. Cheaper and advancement in digital device technology such as Android setup box, Android TV, 3D TV, 4K TV, 2K mobile display with 5G network may help OTT to gain its market. There will be no difference in video editing as OTT is concerned. Editing changes with the subject, but not with an exhibition platform. Hopefully for debut film makes and small budget films OTT may be the noble platform. Quality and content of the cinema should satisfy the subscribers of the particular OTT platform.

A Cinematographer Adwitha expressed that in future OTT may compete with the theatres, because it will have huge content from various languages with different kinds of video formats especially Web series. We should change our working style with regard to OTT. Because when shoot for the theatres we concentrate on showing characters in extralarge size than real one. As OTT is a small screen, characters looks smaller than real life. Even in shot compositions varies for theatres as it demands wide and establishing shots. But in OTT we have to compose shots carefully. We should be more responsible as we are competing with world cinema and should maintain international standard with OTT. Right now there are more opportunities for Kannada web series and films on OTT. But our making and presentation should satisfy the larger audience. This is the major challenge.

Another Director Udaya Prasanna, reacted that, for small budget, new talents and for experimental films OTT is the best option. But, there should be no difference in treatment for OTT and theatrical release especially in story and presentation. Kannada film industry is facing many challenges and opportunities in both the platforms. For theatrical release dubbing, domination by neighbor state film, distribution and availability of theatres are the major challenges and for OTT revenue, reaching Kannada audience, competing with world cinema are the challenges. According to Soonya, a Kannada film debut director, script writer should not corrupt during conceiving the idea and development story. He/she should think of it in a broader concept and later during production or while storyboard they may adopt the story to match the exhibition platform. Mr. Arjun, Kannada film actor opined that heroes have followers. Fans always eagerly wait for their hero's film to be released. That celebration may miss in OTT release.

\section{CONCLUSION}

The study revealed that in future also audience prefers to watch movies in theatre and OTT will be their second choice. Although they are comfortable watching movies on small screens, majority of the respondents like to enjoy or feel the movie in theatrical atmosphere. There are less number of respondents who agreed that they get theatrical feeling on small screens. In the interview majority of them did not agree that OTT will be the future of Kannada cinema exhibition. As revenue from theatrical release is higher than OTT, it will be the second source of income for the producer. With regard to camera work, the majority of them agreed that camera composition may change while producing the movie for OTT. There is a need to adopt international standard in presentation. OTT platforms should strictly impose the regulations to avoid the content which affects the laws and ethics of the country or film makers voluntarily adhere to self-regulation with respect to the content. Small budget and debuts are interested to release their film on OTT, but big budget film makers considered OTT as their second option. Artiststhinks that releasing a movie on OTT may decrease star value. Therefore, the study concluded that audience and film makers are not ready to accept the OTT as platform for film release. But, they also knew that it will be inevitable during the situation like COVID-19 or in the upcoming digital world.

\section{REFERENCES}

[1] Community. (2020, November 26). Future of OTT in India. Community.https://community.nasscom.in/communities/digitaltransformation/telecom-media-communities/future-of-ott-inindia.html.

[2] Ghadialy, Z. (2011). Mobile TV Technology, Retrieved 02 02, 2021,fromhttps://www.3g4g.co.uk/Other/Tv/Presentations/mobile_tv _introduction.pdf.

[3] IANS. (2019, July 19). Four Out of Five Smartphone Owners in India Use At Least One OTT Entertainment App. News 18. https://www.news18.com/news/tech/four-out-of-five-smartphoneowners-in-india-use-at-least-one-ott-entertainment-app2236955. html.

[4] Jyoti, K. (2020, December 22). Laxmii to Dil Bechara, big Bollywood films released on OTT in 2020. India Today. https://www.indiatoday.in/movies/bollywood/story/laxmii-to-dilbechara-big-bollywood-films-released-on-ott-in-2020-1751978-202012-22.

[5] Pawan, L., \& Kamal, K. (2020, June 29). Is Direct Digital Release a Threat to Theaters? IIMB. https://www.iimb.ac.in/turn_turn/is-directdigital-release-threat-theaters.php

[6] Priyal, P. (2020, July 24). The dusk of cinema or the dawn of digital? ORF. https://www.orfonline.org/expert-speak/the-dusk-of-cinema-orthe-dawn-of-digital/

[7] Shashank, S. (2020, September 9). OTT: Technology, Censorship AndTheFuture.Forbes.https://www.forbes.com/sites/forbestechcounci 1/2020/09/09/ott-technology-censorship-and-the future/?sh= 2bfb5f707721. 